\title{
QSAR, ADME and docking guided semi-synthesis and in vitro evaluation of 4-hydroxy-a-tetralone analogs for anti-inflammatory activity
}

\author{
Harish C. Upadhyay ${ }^{1,2} \cdot$ Monika Singh $^{3} \cdot$ Om Prakash ${ }^{4} \cdot$ Feroz Khan $^{4} \cdot$ Santosh K. Srivastava ${ }^{2}$ (I) . \\ Dnyaneshwar U. Bawankule ${ }^{3}$
}

Received: 13 August 2020 / Accepted: 29 October 2020 / Published online: 24 November 2020

C) Springer Nature Switzerland AG 2020

\begin{abstract}
The compound 4-hydroxy-a-tetralone (1) is major bioactive secondary metabolite of genus Ammannia (Family- Lythraceae). The compound $\mathbf{1}$ and its various derivatives are reported to possess anti-tubercular, anti-diabetic, anti-leishmanial and bioenhancing activities. A quantitative structure activity relationship (QSAR) model for predicting anti-inflammatory activity of 4-hydroxy-a-tetralone derivatives against the tumour necrosis factor (TNF)- $a$, a pro-inflammatory cytokine was developed by non-linear model using artificial neural network (ANN). The regression coefficient $\left(r^{2}\right)$ and the leave-oneout cross-validation regression coefficient $\left(\mathrm{LOO} \mathrm{rCV}^{2}\right)$ of the QSAR model were 0.6976 and 0.4016 , respectively, while the regression coefficient $\left(r^{2}\right)$ for the external set of experimental compounds was 0.835 . The 4-hydroxy-a-tetralone virtual derivatives, which showed significant inhibition of TNF-a were subjected to docking and in-silico absorption, distribution, metabolism and excretion (ADME) studies and the results showed similar binding affinity and bioavailability in compliance with the standard drug, Diclofenac. Finally, in order to validate the developed QSAR model, the most and least active virtual derivatives were semi-synthesized, characterized on the basis of their ${ }^{1} \mathrm{H}$ and ${ }^{13} \mathrm{C}$ NMR spectroscopic data and in vitro tested for concentration dependent inhibition of TNF-a. The experimental results obtained, agreed well with the predicted values.
\end{abstract}

Keywords QSAR·Docking · Anti-inflammatory $\cdot \mathrm{TNF}-\mathrm{a} \cdot$ Ammannia baccifera $\cdot$ In vitro studies

\section{Introduction}

Inflammation is a natural defence mechanism caused by a variety of stimuli including microbial invasion, physical damage, ultra-violet irradiation and immune reactions [1,
2]. Inflammation cascades can lead to variety of diseases like chronic asthma, rheumatoid arthritis, osteoarthritis, multiple sclerosis, inflammatory bowel disease (IBD), and psoriasis prevailing in aging society of entire world [3-5]. Osteoarthritis, a chronic inflammatory disease is

Harish C. Upadhyay and Monika Singh contributed equally to this research.

Electronic supplementary material The online version of this article (https://doi.org/10.1007/s42452-020-03798-5) contains supplementary material, which is available to authorized users.

Feroz Khan, f.khan@cimap.res.in; $₫$ Santosh K. Srivastava, skscimap@gmail.com; $\bowtie$ Dnyaneshwar U. Bawankule, du.bawankule@ cimap.res.in | ${ }^{1}$ Medicinal Chemistry Department, CSIR-Central Institute of Medicinal and Aromatic Plants, P.O.-CIMAP, Lucknow 226015, India. ${ }^{2}$ Laboratory of Chemistry, Department of Applied Sciences, Rajkiya Engineering College (Affiliated with Dr. A.P.J. Abdul Kalam Technical University, Lucknow), Churk, Sonbhadra 231206, India. ${ }^{3}$ Molecular Bio-Prospection Department, CSIR-Central Institute of Medicinal and Aromatic Plants, P.O.-CIMAP, Lucknow 226015, India. ${ }^{4}$ Metabolic and Structural Biology Department, CSIR-Central Institute of Medicinal and Aromatic Plants, P.O.-CIMAP, Lucknow 226015, India. 
characterized by loss of joint cartilage leading to pain and loss of function, primarily in the knees and hips $[6,7]$. It is one of the most common types of arthritis affecting $9.6 \%$ of men and $18 \%$ of women aged more than 60 years [7]. WHO projects osteoarthritis to be the fourth leading cause of disability in aging population of the world by the year 2020 [8]. Moreover, it is now globally accepted that chronic inflammation is one of the major risk factors for development of various types of cancer [3,9]. Diverse reactive oxygen species (ROS) and reactive nitrogen species (RNS) such as superoxide anion $\left(\mathrm{O}_{2}^{-}\right)$, hydroxyl radical $(\mathrm{OH})$, hydrogen peroxide $\left(\mathrm{H}_{2} \mathrm{O}_{2}\right)$, nitric oxide (NO), and singlet oxygen $\left({ }^{1} \mathrm{O}_{2}\right)$ generated by inflammatory cells, injure cellular biomolecules including nucleic acids, proteins and lipids, causing cellular and tissue damage, which in turn augments the state of inflammation $[2,5,10]$. Immune cells are particularly important in inflammation because they play the key role in release of several mediators of defence process such as enzymes, cytokines, prostaglandins and nitric oxide [2, 5]. However, uncontrolled production of these mediators is associated with tissue damage due to oxidative stress $[11,12]$. Tumor necrosis factor (TNF)- $\alpha$ is a cytokine, involved in systemic inflammation that stimulate the acute phase reaction. Primarily, TNF- $a$ is produced by immune cells such as monocytes and macrophages in response to immunological challenges like microorganisms, microbial products (viz. endotoxins), lipopolysaccharide (LPS) and lymphokines $[12,13]$. TNF-a play important role in antitumor activity, immune modulation, inflammation, anorexia, cachexia, septic shock, viral replication and hematopoiesis [13-15]. Thus, TNF-a is a central regulator of inflammation, and TNF- $\alpha$ antagonists may be effective in treating inflammatory disorders $[15,16]$. LPS is a major component of the cell wall of gram-negative bacteria, known to stimulate the macrophage secretion of nitric oxide and inflammatory cytokines such as TNF- $a$ and interleukin-1-beta (IL-1-beta) $[17,18]$. Both steroidal and non-steroidal class of drugs are popularly used for treatment of inflammation. The common nonsteroidal anti-inflammatory drugs (NSAIDs), such as Aspirin, Diclofenac, Ibuprofen, Indomethacin etc. as well as corticosteroids are associated with several adverse effects $[4,19,20]$. Corticosteroids are common treatment for rheumatoid arthritis and IBD's, but their long time use cause some serious adverse effects, including hypertension, hyperglycemia, muscular weakness, increased susceptibility to infection, osteoporosis, glucoma, psychiatric disturbances, and growth arrest [20,21].

The natural product based remedy, mainly plants has been used since the beginning of human civilization as folklore or as orderly-regulated systems of indigenous medicines viz. traditional Chinese medicine, Ayurveda, Kampo, traditional Korean medicine and Unani $[22,23]$. Due to existence of diverse range of pharmacologically active chemical entities, plants are still of continued interest to modern pharma scientists because compounds existing in plants have better compatibility to human body, hence lesser side effects [22-24]. There are several records in traditional medicine on use of medicinal plants in case of pain and inflammation, which was further verified by isolation of anti-inflammatory drugs from plants like aspirin $[4,25]$. Several other molecules of plant origin are either being used as a drug or in clinical trials as promising targets to treat inflammatory diseases. Some of them are Epigallocatechin-3-gallate from Camellia sinensis, Triptolide from Tripterygium wilfordii, Boswellic acid from Boswellia serrata, Andrographolid from Andrographis paniculata, Curcumin from Curcuma longa, colchicines from Colchicum autumnale, capsaicin from Capsicum species and Honokiol from various Magnolia species [4, 5, 25]. The plant secondary metabolites mainly phenolics act as reducing agents either by donating hydrogen atom and/ or by quenching singlet oxygen to remove reactive oxygen species (ROS) from living system, justifying their antioxidant activities [11]. Further, these natural antioxidants regulate the production of pro-inflammatory mediators TNF-a, leukocyte adhesion, and nitric oxide (NO) playing a crucial role in immune-inflammatory response $[14,15]$. Thus, natural product based novel leads offer a great hope for the development of valid alternative to existing drugs with cost-effectiveness and lesser side effects for treating inflammatory diseases.

QSAR, ADME and docking have become inexorably embedded as essential tools in the pharmaceutical industry, from lead discovery, optimization to the lead development and computer-aided drug designing [26]. A growing trend is to use these modern techniques in early stage of drug discovery process as a screening and enrichment tool to eliminate the compounds lacking drug like properties from further development process $[26,27]$. The structurally related properties of a compound can be determined by computational mean much more efficiently in quicker and easier mode than its biological activity $\left(\mathrm{LD}_{50} / \mathrm{IC}_{50} / \mathrm{ED}_{50}\right)$ using in vivo or in vitro approaches. A statistically validated QSAR model is capable of predicting the biological activity of a new compound within the same series many times faster than the intensive processes of chemical synthesis and biological evaluation. When applied judiciously, QSAR, ADME and docking can save a substantial amount of time, money and human resources [28].

The compound 4-hydroxy-a-tetralone (1) and its glucoside (2) have been isolated as a major bioactive compound from various species of Ammannia (Lythraceae) [29-31]. In continuation of our efforts to explore the biological potential of 4-hydroxy-a-tetralone derivatives [32-34], the compounds ( 1 \& 2) were isolated from $A$. baccifera; a plant of high medicinal value used in herbal 
formulations in cancer, spinal disease, human female infertility, chronic tonsillitis, pelvic inflammatory disease, treatment of bladder stones, urinary tract infections, dermatitis. The isolated tetralone derivatives ( 1 \& 2) showed significant inhibition of TNF-a, suggesting for the possible use of $\mathbf{1}$ and its various analogs as antiinflammatory drugs. This prompted us to develop and validate a QSAR model for predicting anti-inflammatory activity of 4-hydroxy-a-tetralone derivatives against the TNF-a. A total of 28 virtual analogs of 4-hydroxya-tetralone were screened using this developed QSAR model, and the model predicted that a few analogues possess high, while others possess low anti-inflammatory activity. To validate the predictions made by the model, semi synthesis of few highly and low active analogs was carried out in the wet lab, and experimentally evaluated there in vitro anti-inflammatory activity by quantification of TNF-a. In this way, 4-hydroxy-atetralone analogs can be designed with enhanced antiinflammatory activity using QSAR model and in silico pharmacokinetics compliance (ADME).

\section{Materials and methods}

\subsection{In silico studies}

\subsubsection{Molecular descriptors and structure cleaning}

The 2D structures of various tetralone derivatives drawn with ChemDraw-Ultra, were transformed into 3D and geometry was cleaned using ChemBioDraw-Ultra-v12.0 (http://www.cambridgesoft.com). Energy minimization was performed withMM2/MM3 molecular mechanics parameter until achieving the lowest stable energy $(<0.001 \mathrm{kcal} / \mathrm{mol})$ [35]. The 3D chemical structure of standard drug Diclofenac (DB00586) was retrieved from the PubChem compound database at NCBI (http://www. pubchem.ncbi.nlm.nih.gov). Crystallographic 3D structures of target protein TNF-a (PDB: 2AZ5) was retrieved from the Brookhaven Protein Databank (http://www. pdb.org). Molecules for dataset of QSAR model were collected from Niwayama et al. 1996 [38] with molecule IDs: CHEMBL468, CHEMBL11440, CHEMBL88935, CHEMBL99900, CHEMBL105402, CHEMBL275009, CHEMBL319245, CHEMBL319803 and CHEMBL330174 as known inhibitors of TNF-a. The PaDEL descriptor software (National University of Singapore) was used to calculate molecular structure descriptors, which contain CDK-library to calculate descriptors.

\subsubsection{ANN based non-linear QSAR modelling}

In the present study, percentage inhibition activity pattern against TNF- $a$ was captured in the form of QSAR model. The molecular properties and their respective bioactivity values have been fitted into the polynomial equation map. A series of data generated from the equations has been used as input and output value for analysis in the back propagation neural network (BPNN) model. In order to build reliable and predictive QSAR model, we adopted the ANN technique, which has been proven to have outstanding non-linear approximation ability [36, 37]. In ANN architecture, the neurons are arranged in layers (input, hidden and output), and unidirectional connections. The adjacent layers are fully connected but no connections exist between the neurons within the same layer. The signals are propagated from the input neurons through the hidden layer to the output neuron, and then the error is calculated and back propagated to iteratively adjust weights and biases in order to minimize the error in prediction; this is the most distinct character of typical back propagation (BP) algorithm. The ANN program used was the neural network software package of MATLAB v2012 developed by the MathWorks, USA (http://www.mathworks.com/). Some fully connected 3-layer BP neural networks with sigmoid transfer function were constructed. The number of neurons in the input layer equalled the number of selected descriptors. Before the network training, all of the input and output values were normalized to between 0.1 and 0.9 , and the outputs were transferred back to the same units as the original outputs for comparison purpose. The Levenberg-Marquardt algorithm was adopted to optimise weights and biases because it was significantly faster than other algorithms based on gradient descent $[36,37]$. The experimental dataset as well as independent external testing set was used to evaluate the predictive ability of the models. Performance of the model has been evaluated by the regression coefficients as: $R^{2}$ for training data, $R^{2}$ for LOO cross validation, $R^{2}$ for optimization set, $R^{2}$ for external set experimental compounds.

\subsubsection{Molecular interaction and bioavailability study}

Docking study was performed with Autodock Vina v0.8 (Molecular Graphics Lab at The Scripps Research Institute, La Jolla, CA 92037, USA) with Lamarkian Genetic algorithm for grid based searching of most optimal binding pose of tetralones and Diclofenac with anti-inflammatory target TNF-a following earlier described procedures [12, 35]. Bioavailability was screened through absorption, distribution, metabolism and excretion (ADME) parameters [12, 35]. 


\subsection{Chemistry}

\subsubsection{General experimental procedures}

The $300 \mathrm{MHz}$ NMR (Avance, Bruker, Switzerland) was used to record ${ }^{1} \mathrm{H}$ and ${ }^{13} \mathrm{C}$ NMR with tetramethylsilane (TMS) as internal standard. Hyphenated LC-PDA-MS (Prominence LC and mass MS-2010EV, Shimadzu, Japan) was used for mass spectra. TLC plates (silica gel $60 \mathrm{~F}_{254}$, Merck) were first examined under UV illumination at 254 and $365 \mathrm{~nm}$ and then sprayed with vanillin-sulphuric acid $(1: 5, \mathrm{w} / \mathrm{v})$ solution in ethanol followed by heating at $95^{\circ} \mathrm{C}$ for $5 \mathrm{~min}$. The solvents used in extraction and fractionation were purchased from by Merck India Pvt. Ltd. and other chemicals were purchased from Sigma-Aldrich Pvt. Ltd., India.

\subsubsection{Isolation and chemical transformation of compounds}

The samples of $A$. baccifera (CIMAP Herbaruim voucher No.9460) were collected from local areas near the institute. The shade dried powdered plant material was extracted with methanol. The dried methanol extract was dissolved in hot water and then fractionated using $n$-hexane, chloroform and $n$-butanol. The compounds 1 and $\mathbf{2}$ (Fig. 1) were isolated through repeated chromatographic separations from chloroform and $n$-butanol fractions respectively [29,
30]. Further, compound 1 was chemically transformed in to its two semi-synthetic aryl ester derivatives (1 b \& 1d) following earlier described procedures [32-34]. In brief, for each reaction, the compound 1 (50 $\mathrm{mg}$ ) was dissolved in dry pyridine and benzoyl/3,4,5-trimethoxybenzoyl chloride (1.5 molar ratio), catalytic amount of 4-dimethylaminopyridine (DMAP) was added and left overnight at room temperature $\left(30-35^{\circ} \mathrm{C}\right)$. Progress of the reaction was monitored by TLC. Crushed ice was added to the reaction mixture, extracted with chloroform and the solvent removed from chloroform extract. Further purification of organic extract by column chromatography applying gradient elution with solvents of increasing polarity using hexane and chloroform in various proportions afforded the respective derivatives, 1b \& 1d in 90 \& 85\% yields respectively. The spectroscopic data of compounds are given in supplementary file.

\subsection{In vitro studies}

\subsubsection{In vitro anti-inflammatory activity}

Isolation of murine peritoneal macrophage cells was carried out as described previously [39]. The viable cells $\left(5 \times 10^{5}\right.$ cells $\left./ \mathrm{mL}\right)$ were suspended in Dulbecco's Modified Eagle's medium (DMEM, Sigma-Aldrich, USA) containing

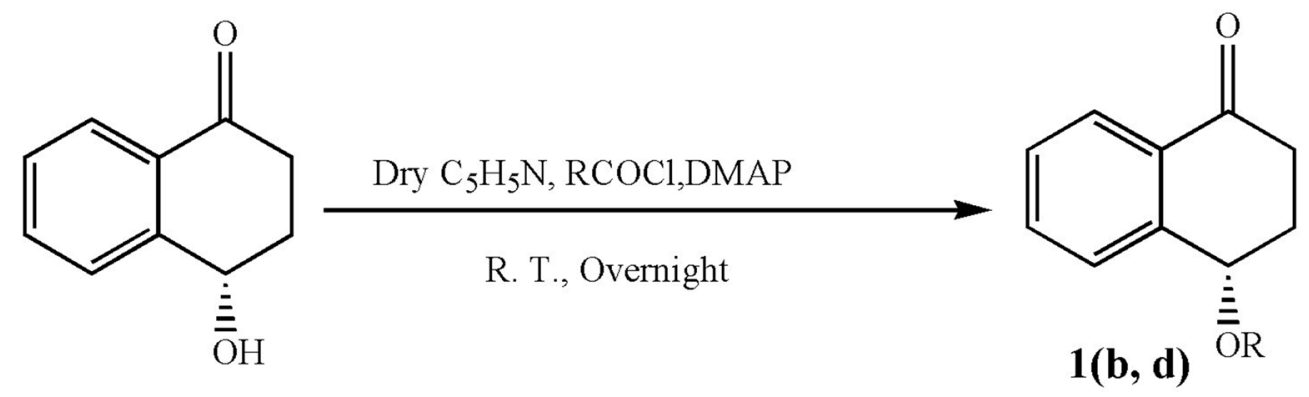

1<smiles>O=C1CC[C@H](OC2OC(CO)C(O)C(O)C2O)c2ccccc21</smiles>

2<smiles>[R][As]S(=O)(=O)c1ccccc1</smiles><smiles></smiles>

Fig. 1 Structure of the isolated compounds and derivatives 
$10 \%$ heat-inactivated fetal bovine serum (Gibco, USA) and incubated in a culture plate at $37{ }^{\circ} \mathrm{C}$ in $5 \% \mathrm{CO}_{2}$ in an incubator. Cells were pre-treated with 5,10 and $20 \mu \mathrm{g} / \mathrm{mL}$ of test compounds and standard anti-inflammatory drug, Diclofenac sodium (Sigma Aldrich, USA) separately, at $10 \mu \mathrm{g} / \mathrm{mL}$ for $30 \mathrm{~min}$. Then after, the cells were stimulated with lipopolysaccharide (LPS, $1 \mu \mathrm{g} / \mathrm{mL}$. After incubation with LPS for $18 \mathrm{~h}$, supernatants were collected and immediately frozen at $-80^{\circ} \mathrm{C}$. The harvested supernatants were tested for quantification of pro-inflammatory mediator (TNF-a) by EIA kits (BD Biosciences, USA) following the manufacturer's protocol and earlier described procedure [40]. The percentage TNF-a inhibition was calculated as follows:

\%inhibition $=100 \times(\mathrm{OD}$ of control $-\mathrm{OD}$ of sample $) / O D$ of control

where control indicates cells treated in LPS alone.

\subsubsection{Cell viability assay}

The inhibitory effects of test compounds on peritoneal macrophage cell growth were tested using the 3-(4,5-dimethylthiazole-2-yl)-2,5-biphenyltetrazolium bromide (MTT) [41]. Cells were seeded at a density of $1 \times 10^{6}$ cells/well in a 96-well plate and incubated for $24 \mathrm{~h}$ at $37^{\circ} \mathrm{C}$ and $5 \% \mathrm{CO}_{2}$. Cells were then treated with test compounds and incubated for another $24 \mathrm{~h}$, after which the MTT solution at $2 \mathrm{mg} / \mathrm{mL}$ was added for $1 \mathrm{~h}$. The MTT containing medium was carefully removed and the cells were solubilised in DMSO $(100 \mu \mathrm{L})$ for $10 \mathrm{~min}$. The extent of the reduction of MTT to formazon within cells was quantified by measuring the optical density at $570 \mathrm{~nm}$ using Molecular Device microplate reader (Spectramax; Molecular Devices, USA). The average optical density formed in control cells were taken as $100 \%$ viability and the results of treatments were expressed as a percentage of the control.

\subsubsection{Statistical analysis}

The data collected were compiled and analyzed using GraphPad Prism 4. The ANOVA followed by Bonferroni post-test were used to assess the statistical significance of various groups. Results are presented as the means \pm SE. Differences with a $P$ value $<0.05$ were considered significant.

\section{Results and discussion}

\subsection{Non-linear QSAR modelling}

In order to virtually screen the derivatives of 4-hydroxya-tetralone (1), an ANN based QSAR model was built with the help of other molecules possessing similar structural as well as functional properties. The ANN (using feed forward back propagation method) based non-linear QSAR model was developed for percentage inhibition as dependent variable and derived independent variables which are the basic requirement for model development. Firstly, all compounds were prepared for QSAR, and then the biological activities were specified as dependent property. Concentration along with molecular descriptors was processed for calculation of independent variables for model building. Diclofenac was taken as positive control for similar activity. Molecular descriptors with least interdependencies were used for QSAR modelling. In present study, 13 orthogonal components derived from 2D molecular descriptors along with concentration of lead molecules were used for QSAR model development. These orthogonal components provide pattern in high dimension feature space for mapping of consensus diversification of active compounds. The model was optimised for tetralone pharmacophore. The regression coefficient $\left(r^{2}\right)$ and LOO crossvalidation regression coefficient $\left(\mathrm{LOO} \mathrm{rCV}^{2}\right)$ of the QSAR model were 0.6976 and 0.4016 , respectively. The other model evaluation parameters were as: $R^{2}$ for optimization set: $0.733, R^{2}$ for external set experimental compounds: 0.835 . Architecture for ANN-QSAR model is as: Input, hidden, output $=13,4,1$. Learning of model was processed for one thousand epochs with momentum of 0.555556 and learning rate of 0.222222 . Initial weights of the neural network were ranging between \pm 0.5 , while data normalization was done between 0.1 and 0.9 . The training data contains optimization set molecules, which were used to mould the tendency of model for prediction of specific pharmacophores (Fig. 2).

\subsection{Screening of 4-hydroxy-a-tetralone virtual derivatives through the developed QSAR model}

For predicting anti-inflammatory activity by the developed QSAR model, 28 new derivatives of 4-hydroxy-atetralone (1) were designed and screened for their TNF- $a$ inhibiting potential along with $\mathbf{1}$, its glucoside (2) and the positive control, Diclofenac. Out of 28 derivatives, only 12 were in the applicability domain of the model and the results of their respective percentage inhibition 
Fig. 2 Regression plot of ANNQSAR model

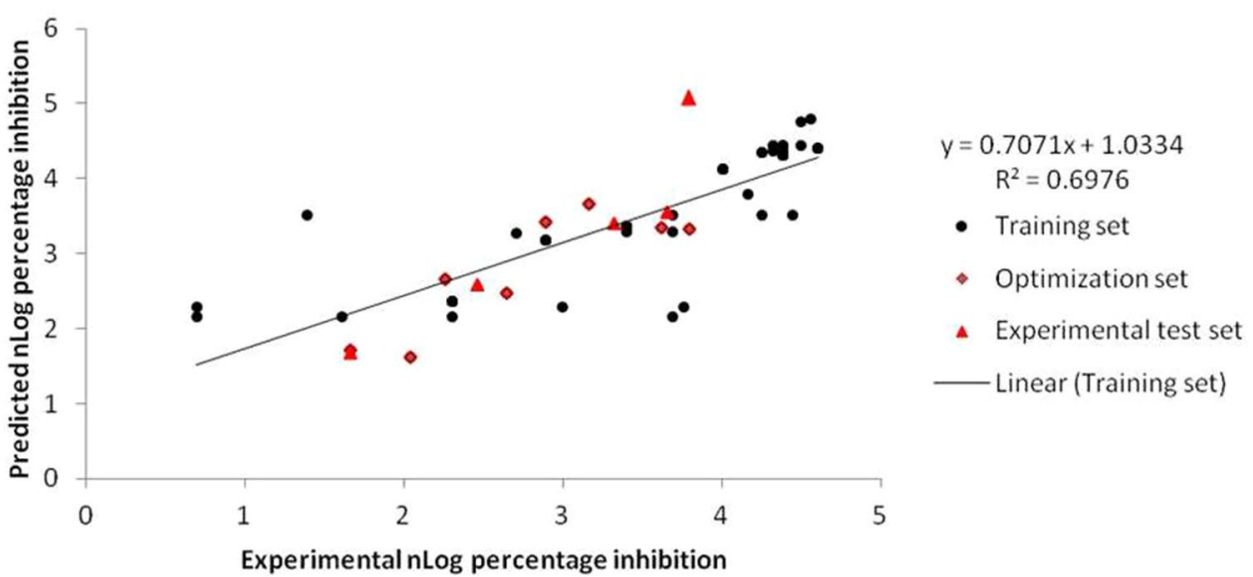

of TNF- $a$ at $10 \mu \mathrm{g} / \mathrm{mL}$ concentration is given in Table 1 below, while the results of rest of the virtual derivatives are given in supplementary file.

From the above table, it is evident that the most active virtual derivative was $\mathbf{1 b}$ (34.78\% inhibition) followed by compound 1 (29.85\% inhibition). The increased TNF-a inhibitory activity of $\mathbf{1} \mathbf{b}$ is plausibly due to its greater hydrophobic interaction with aromatic amino acids of the pro-inflammatory cytokine, TNF-a.

\subsection{Docking study}

The aim of the molecular docking study was to elucidate whether 4-hydroxy-a-tetralone derivatives modulate the anti-inflammatory target and also to identify the binding site against well-known human anti-inflammatory molecular target TNF-a. The docking was performed on $\mathbf{1}$ and its virtually active derivatives ( $\mathbf{1} \mathbf{b} \& \mathbf{1}$ d) with Diclofenac for their binding affinity with TNF-a. The results (Fig. 3 ) indicate that these compounds have similar range of binding affinity as that of Diclofenac sharing common residues at binding pockets: TYR-119C, GLY121C, LEU-120C, TYR-59C \& TYR-151C from chain-C and TYR-59D \& TYR-1 19D from chain-D of TNF-a. The derivative $\mathbf{1} \mathbf{b}$ showed highest binding affinity $(-6.7 \mathrm{kcal} / \mathrm{mol})$ even better than the positive control, Diclofenac.

\subsection{Bioavailability study}

The drug likeliness of 4-hydroxy-a-tetralone (1), its glucoside (2) and semi-synthetic analogues $\mathbf{1} \mathbf{b}$ and $\mathbf{1} \mathbf{d}$ was assessed through Lipinski's rule of five and the results showed (Table 2) that none of the active molecules violated the Lipinski's rule and showed compliance with positive control Diclofenac.

\section{5 e-Toxicity study}

The e-toxicity prediction for the experimentally validated molecules $\mathbf{1}, \mathbf{2}, \mathbf{1 b}, \mathbf{1} \mathbf{d}$ and the positive control, Diclofenac was performed by pancreatic cancer cell (PaCa2) cellular uptake, which provides the response of cancerous cells for the molecules under study. The results are given in Table 3 below.

From Table 5, it is evident that experimentally tested molecules $\mathbf{1}$ and $\mathbf{1 b}$ shows compliance with control and possess positive attitude of cellular uptake. These predictions have been made with $80 \%$ confidence. The most potent derivative $\mathbf{1} \mathbf{b}$ did not show any hepatotoxicity, while the positive control Diclofenac showed hepatotoxicity.

\subsection{Experimental validation of ANN-QSAR based predictions}

The isolation of 4-hydroxy-a-tetralone (1) and its glucoside (2) was carried out from the chloroform and $n-\mathrm{BuOH}$ fractions of $A$. baccifera following earlier described procedures. Further, the most (1 $\mathbf{b})$ and least (1d) active virtual analogs of $\mathbf{1}$ were semi-synthesized and characterized on the basis of their ${ }^{1} \mathrm{H}$ and ${ }^{13} \mathrm{C}$ NMR spectroscopic data (Fig. 1) [32-34]. The anti-inflammatory potential of compounds $\mathbf{1}, \mathbf{2}, \mathbf{1} \mathbf{b}$ and $\mathbf{1} \mathbf{d}$ was assessed in vitro in terms of quantification of TNF- $\alpha$ inhibiting potential at 5,10 and $20 \mu \mathrm{g} / \mathrm{mL}$ concentrations. The results indicate that $\mathbf{1}$, its glucoside (2) and the semi-synthetic analogues $\mathbf{1} \mathbf{b}$ and $\mathbf{1} \mathbf{d}$ possess moderate to significant TNF-a inhibiting property in a concentration dependent manner (Table 4).

The TNF- $a$ inhibiting potential increased by increasing the concentration of the test compounds. Among the tested compounds, the benzoyl derivative (1 $\mathbf{b})$ showed maximum inhibition of TNF-a $(23.57 \%, 38.75 \%$ and $44.46 \%)$ followed by 1 (18.02\%, $27.58 \%$ and $37.33 \%)$ 
Table 1 Prediction for \% inhibition of TNF-a by 4-hydroxy-atetralone derivatives

\begin{tabular}{ll}
\hline Molecule Structure & \% inhibition of \\
& TNF- $a$ at $10 \mu \mathrm{g} /$ \\
$\mathrm{mL}$
\end{tabular}

1<smiles>O=C1CC[C@H](O)c2ccccc21</smiles>

29.85045253

2<smiles>O=C1CC[C@H](OC2OC(O)C(CO)C(O)C2O)c2ccccc21</smiles>

13.35833<smiles>COc1cccc(C(=O)O[C@H]2CCC(=O)c3ccccc32)c1</smiles>

1b<smiles>O=C(O[C@H]1CCC(=O)c2ccccc21)c1ccccc1</smiles>

15.69261156
Table 1 (continued)

Molecule Structure

$\%$ inhibition of TNF-a at $10 \mu \mathrm{g} /$ $\mathrm{mL}$

$1 d$<smiles>COc1cc(C(=O)O[C@H]2CCC(=O)c3ccccc32)cc(OC)c1OC</smiles>

$1 \mathrm{~g}$<smiles>CC(=O)O[C@H]1CCC(=O)c2ccccc21</smiles>

5.368668896

$1 \mathrm{p}$<smiles>C/C=C/CC(=O)O[C@H]1CCC(=O)c2ccccc21</smiles>

20.07469366

19<smiles>C/C=C/C(=O)O[C@H]1CCC(=O)c2ccccc21</smiles> 
Table 1 (continued)

Molecule Structure

1r<smiles>CCCCC(=O)O[C@H]1CCC(=O)c2ccccc21</smiles>

$1 \mathbf{t}$<smiles>C=CC(=O)O[C@H]1CCC(=O)c2ccccc21</smiles>

1u<smiles>C=CCCC(=O)O[C@H]1CCC(=O)c2ccccc21</smiles>

$1 \mathbf{x}$<smiles>Cc1ccc(C(=O)O[C@H]2CCC(=O)c3ccccc32)cc1</smiles>

$\%$ inhibition of TNF-a at $10 \mu \mathrm{g} /$

$\mathrm{mL}$

18.43627147

17.81445132

22.22238246

13.97499973
Table 1 (continued)

Molecule Structure $\%$ inhibition of TNF-a at $10 \mu \mathrm{g} /$ $\mathrm{mL}$

1 aa<smiles>COCC1OC2COC1C(OC)C(OC)O[C@@H]1c3ccccc3C(=O)CC[C@H]1O2</smiles>

4.414170791

$1 \mathrm{ab}$<smiles>COc1ccc(C(=O)O[C@H]2CCC(=O)c3ccccc32)c(OC)c1</smiles>

at 5,10 and $20 \mu \mathrm{g} / \mathrm{mL}$ concentrations respectively. It would be worth mentioning that the benzoyl derivative of 4-hydroxy-a-tetralone (1 b) at $20 \mu \mathrm{g} / \mathrm{mL}$ concentration was equally active to the standard drug, Diclofenac. Further, on comparing the results, it is evident that the predictions made as percentage inhibition of TNF-a for the molecules $\mathbf{1}, \mathbf{2}, \mathbf{1} \mathbf{b}$ and $\mathbf{1 d}$ by the ANN-QSAR based model showed very high similarity with those obtained from in-vitro results (Table 5). These results validate our developed QSAR model.

\subsection{In vitro cytotoxicity of tetralone derivatives}

In order to ascertain safety profile of compounds, the cell viability was determined using MTT assay. The isolated compounds, 4-hydroxy-a-tetralone (1) and its glucoside 


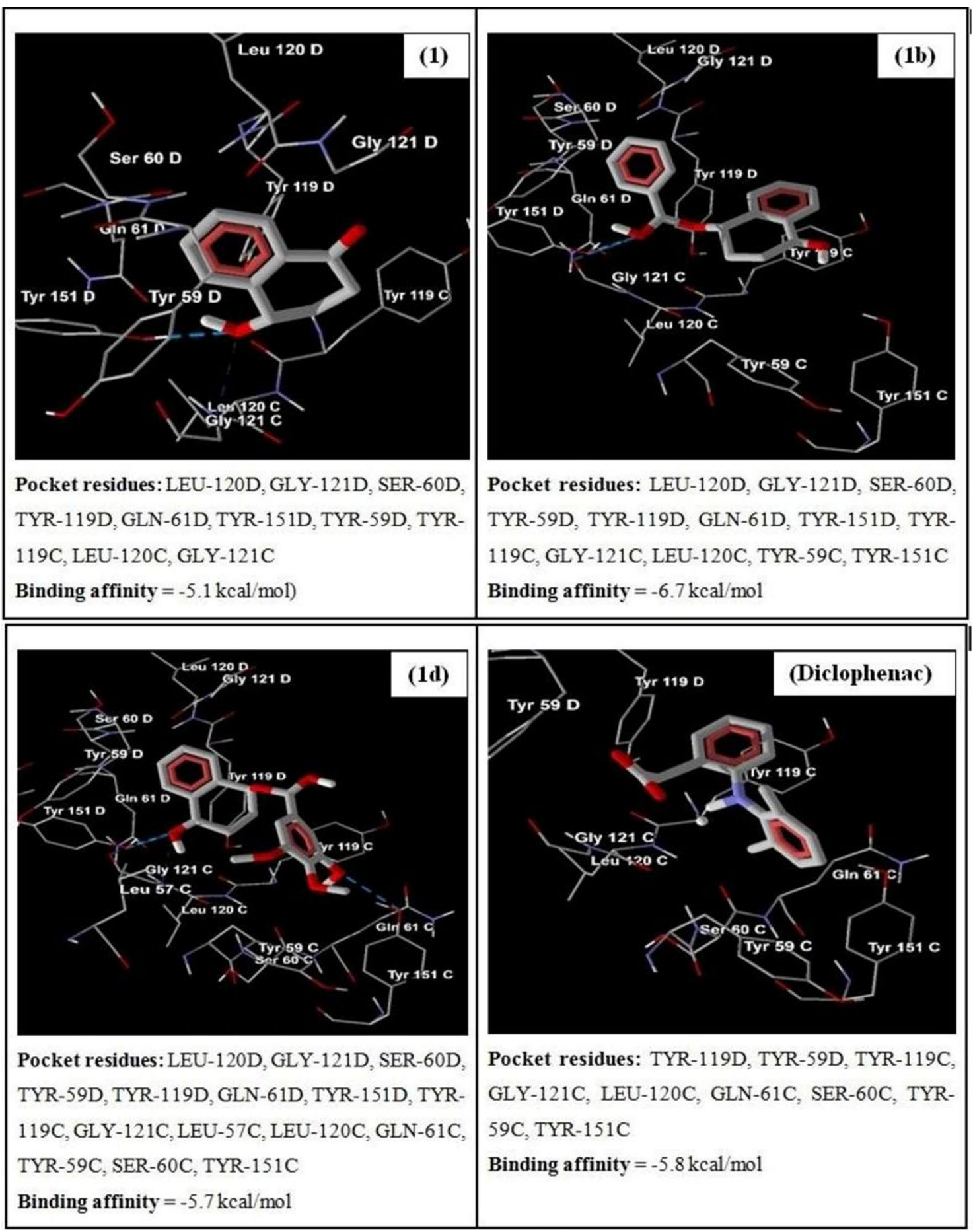

Fig. 3 Compliance of 4-hydroxy-a-tetralone (1), its derivative (1 b \& 1d) and Diclofenac for binding with TNF-a

(2) did not show any cytotoxicity in murine peritoneal macrophage cells at 20,50 and $100 \mu \mathrm{g} / \mathrm{mL}$ concentrations (Fig. 4). From the results, it may be concluded that the decrease in TNF-a concentration was not due to the death of cells.

\section{Conclusion}

ANN based non-linear QSAR model has been developed for in silico prediction of TNF-a inhibition potential of 4-hydroxy-a-tetralone (1) and other structurally related virtual derivatives. The regression coefficient $\left(\mathrm{r}^{2}\right)$ and LOO 
Table 2 Screening of newly designed molecules through Lipinski's rule of five

\begin{tabular}{lllllllll}
\hline Molecule & ALogP & Lipoaffinity Index & nHBAcc & nHBDon & nRotB & $\begin{array}{l}\text { Lipinski } \\
\text { Failures }\end{array}$ & Topo-PSA & MW \\
\hline 1 & -0.0155 & 0.015523 & 2 & 0 & 0 & 0 & 17.07 & 151.9898 \\
$\mathbf{2}$ & -1.7624 & 0.080061 & 7 & 0 & 3 & 0 & 35.53 & 303.9644 \\
1b & 1.5615 & 0.11048 & 3 & 0 & 3 & 0 & 43.37 & 251.9847 \\
1d & 0.0657 & 0.472751 & 6 & 0 & 6 & 0 & 71.06 & 335.9695 \\
Diclofenac & 1.8296 & 0.103383 & 3 & 0 & 4 & 0 & 17.07 & 283.9306 \\
\hline
\end{tabular}

Table 3 e-toxicity prediction for the experimentally validated molecules

\begin{tabular}{lllll}
\hline Compound & $\begin{array}{l}\mathrm{PaCa}_{2} \\
\text { cellular } \\
\text { uptake }\end{array}$ & $\begin{array}{l}\text { Confidence } \\
\left(\mathrm{PaCa}{ }_{2} \text { posi- }\right. \\
\text { tive })\end{array}$ & $\begin{array}{l}\text { Confidence } \\
\left(\mathrm{PaCa}_{2} \text { neg- }\right. \\
\text { ative })\end{array}$ & Hepatotoxic \\
\hline $\mathbf{1}$ & Positive & 1 & 0 & Positive \\
$\mathbf{2}$ & Negative & 0.4 & 0.6 & Positive \\
$\mathbf{1 b}$ & Positive & 1 & 0 & Negative \\
$\mathbf{1 d}$ & Positive & 0.8 & 0.2 & Positive \\
Diclofenac & Positive & 1 & 0 & Positive \\
\hline
\end{tabular}

Table 4 In vitro anti-inflammatory activity of tetralone derivatives

\begin{tabular}{llll}
\hline Treatment & $\begin{array}{l}\text { Concentration } \\
(\mu \mathrm{g} / \mathrm{mL})\end{array}$ & $\begin{array}{l}\text { TNF-a }(\mathrm{pg} / \mathrm{mL}) \\
\text { Mean } \pm \text { SE }\end{array}$ & $\begin{array}{l}\text { \% Inhibi- } \\
\text { tion of } \\
\text { TNF-a }\end{array}$ \\
\hline Normal $^{\mathrm{a}}$ & - & $140.88 \pm 4.86$ & NA \\
Vehicle $^{\mathrm{b}}$ & - & $1162.60 \pm 155.28$ & 00.00 \\
$\mathbf{1}$ & 5 & $953.08 \pm 109.28$ & 18.03 \\
& 10 & $841.98 \pm 67.62$ & 27.59 \\
& 20 & $728.60 \pm 59.72$ & 37.34 \\
1b & 5 & $888.54 \pm 94.10$ & 23.58 \\
& 10 & $712.04 \pm 54.00$ & 38.76 \\
& 20 & $645.73 \pm 70.38$ & 44.47 \\
1d & 5 & $1051.28 \pm 55.91$ & 9.58 \\
& 10 & $1026.43 \pm 67.31$ & 11.72 \\
& 20 & $998.31 \pm 12.99$ & 14.13 \\
2 & 5 & $1101.28 \pm 54.22$ & 5.28 \\
& 10 & $1101.43 \pm 37.76$ & 5.26 \\
& 20 & $1073.31 \pm 79.32$ & 7.68 \\
Diclofenac & 10 & $648.65 \pm 52.26$ & 44.22 \\
\hline
\end{tabular}

${ }^{a}$ Neither treated with LPS, nor with any test compound

${ }^{\text {b}}$ Treated with LPS $(1 \mu \mathrm{g} / \mathrm{mL})$ only

cross-validation regression coefficient $\left(\mathrm{LOO} \mathrm{rCV}^{2}\right)$ of the QSAR model were 0.6976 and 0.4016 , respectively. Screening of virtual analogs of 1 using the derived QSAR model showed that benzoyl derivative (1) $\mathbf{b})$ possesses potent TNF-a inhibiting activity. This analogue on docking studies showed similar binding affinity as that of Diclofenac
Table 5 Experimental validation of ANN-QSAR based prediction

\begin{tabular}{|c|c|c|}
\hline \multirow[t]{2}{*}{ Molecule } & \multicolumn{2}{|c|}{$\%$ Inhibition of TNF- $a$ at $10 \mu \mathrm{g} / \mathrm{mL}$ conc. } \\
\hline & Predicted & Experimental \\
\hline 1 & 29.85 & 27.58 \\
\hline $1 \mathbf{b}$ & 34.78 & 38.75 \\
\hline 1d & 5.36 & 5.26 \\
\hline 2 & 13.36 & 11.71 \\
\hline
\end{tabular}

(positive control) with common residues at binding pocket. Based on bioavailability, drug likeness, ADMET and toxicity risk assessments studies, we concluded that compound $\mathbf{1} \mathbf{b}$ possesses anti-inflammatory potential similar to that of Diclofenac. In order to validate the developed QSAR model, most and least virtually active derivatives were semi-synthesized and in vitro tested for TNF- $a$ inhibition potential. The results obtained agreed well with the predicted values. The analog $\mathbf{1 b}$ showed $44.47 \%$ inhibition of TNF- $\alpha$ at $20 \mu \mathrm{g} / \mathrm{mL}$ concentration which was better than standard drug Diclophenac (44.22\% inhibition) showing at $10 \mu \mathrm{g} / \mathrm{mL}$ concentration. Further, in vitro cytotoxicity study using MTT assay revealed that parent compound (1) and its glucoside (2) did not show any cytotoxicity in murine peritoneal macrophage cells up to $100 \mu \mathrm{g} / \mathrm{mL}$ concentrations. These results offer a useful reference for QSAR and docking guided molecular design of TNF-a inhibitors with improved activity for development of anti-inflammatory leads.

Acknowledgements Authors are thankful to the Council of Scientific and Industrial Research, New Delhi, India for financial support through XII FYP networking project BSC0121 at CSIR-CIMAP, Lucknow, Uttar Pradesh, India. We also thank to Director, CSIR-CIMAP Lucknow for providing necessary research facilities.

\section{Compliance with ethical standards}

Conflict of interest On behalf of all authors, the corresponding author states that there is no conflict of interest. 
Fig. 4 In vitro cell viability assessment of compounds ( 1 \& 2) by MTT assay

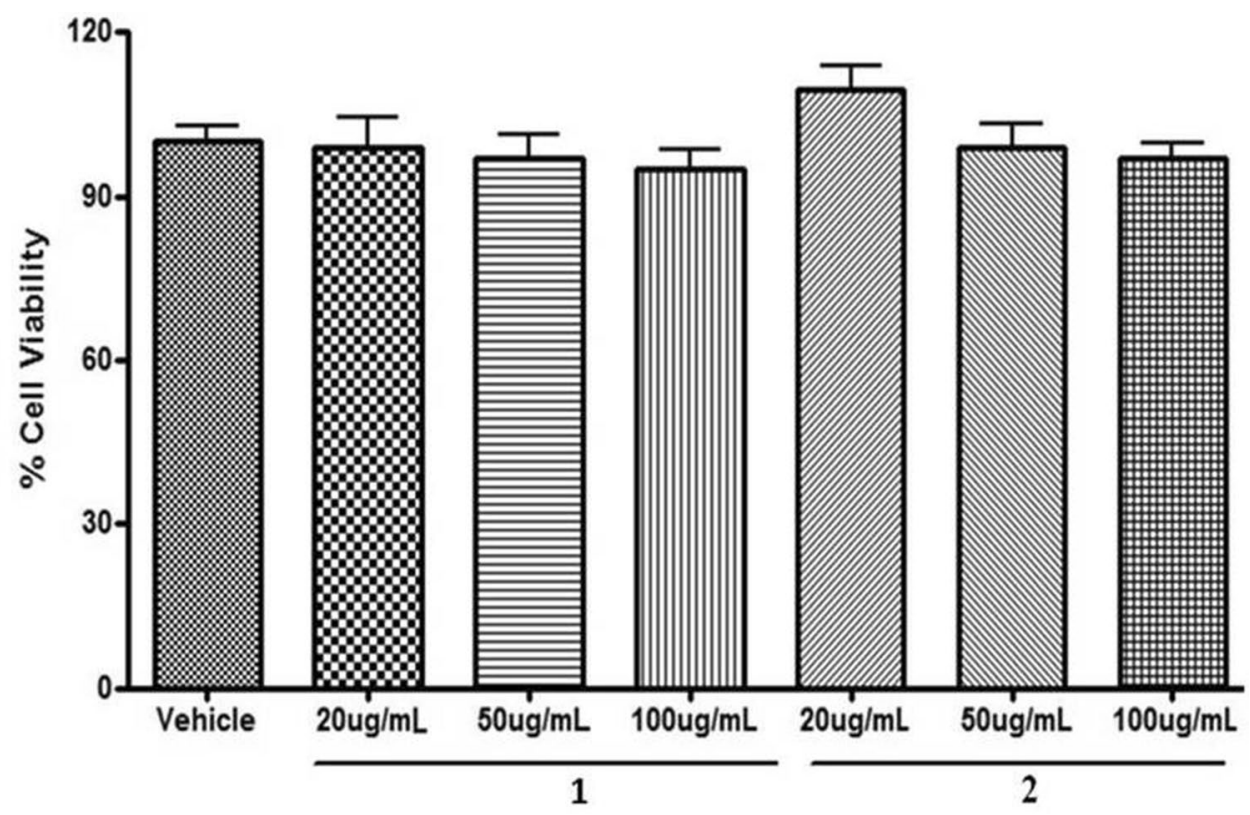

\section{References}

1. Mohan H, Mohan S (2017) Inflammation: acute, in essential pathology for dental students, 5th edn. Jaypee Brothers Medical Publishers, India. https://doi.org/10.5005/jp/books/12923_11

2. Furman D, Campisi J, Verdin E et al (2019) Nat Med 25(12):1822

3. Lu H, Ouyang W, Huang C (2006) Mol Cancer Res 4(4):221

4. Gautam R, Jachak SM (2009) Med Res Rev 29:767

5. Bennett JM, Reeves G, Billman GE, Sturmberg JP (2018) Front Med 5:316

6. Sokolove J, Lepus CM (2013) Ther Adv Musculoskelet Dis 5(2):77

7. WHO Chronic diseases and health promotion. https://www.who. int/chp/topics/rheumatic/en/. Accessed 20 June 2020

8. Smith RJ (2005) Drug Discov Today 10(23-24):1598

9. Coussens LM, Werb Z (2002) Nature 420(6917):860

10. Conner EM, Grisham MB (1996) Nutrition 12(4):274

11. Zhang L, Ravipati AS, Koyyalamudi SR et al (2011) J Agric Food Chem. 59(23):12361

12. Singh $M$, Hamid AA, Maurya AK et al (2014) J Steroid Biochem Mol Biol 143:323

13. Esposito E, Cuzzocrea S (2009) Curr Med Chem 16(24):3152

14. Sullivan GW, Carper HT, Novick WJ Jr, Mandell GL (1988) Infect Immun 56(7):1722

15. Louis E, Franchimont D, Piron A et al (1998) Clin Exp Immunol 113(3):401

16. Ridker PM, Rifai N, Pfeffer M et al (2000) Circulation 101(18):2149

17. Panaro MA, Carofiglio V, Acquafredda A et al (2012) Br J Nutr 108(9):1623

18. Wright SD, Ramos RA, Tobias PS et al (1990) Science 249(4975):1431

19. Jaturapatporn D, Isaac MG, McCleery J, Tabet N (2012) Cochrane Database Syst Rev. https://doi.org/10.1002/14651858.CD006 378.pub2

20. Cho H, Walker A, Williams J, Hasty KA (2015) Biomed. Res Int. https://doi.org/10.1155/2015/595273

21. Bacchi S, Palumbo P, Sponta A, Coppolino MF (2012) Antiinflamm Antiallergy Agents Med Chem 11(1):52

22. Upadhyay HC (2019) Curr Top Med Chem 19(10):784

23. Butler MS, Buss AD (2006) Biochem Pharmacol 71:919
24. Upadhyay HC, Dwivedi GR, Roy S et al (2014) Chem Med Chem 9:1860

25. Oguntibeju OO (2018) J Inflamm Res 11:307

26. Munteanu CR, Fernández-Blanco E, Seoane JA et al (2010) Curr Pharm Des 16(24):2640

27. García-Domenech R, Gálvez-Llompart M, Zanni R et al (2013) Expert Opin Drug Discov 8(8):933

28. Winfield LL, Inniss TR, Smith DM (2009) Chem Biol Drug Des 74(3):309

29. Upadhyay HC, Dwivedi GR, Darokar MP et al (2012) Planta Med 78:79

30. Upadhyay HC, Verma RK, Srivastava SK (2013) J Chromatogr Sci 51(1):21

31. Upadhyay HC, Sisodia BS, Agrawal J et al (2014) Med Chem Res 23:870

32. Upadhyay HC, Jaiswal N, Tamrakar AK et al (2012) Nat Prod Commun 7(7):899

33. Dwivedi GR, Upadhyay HC, Yadav DK et al (2014) Chem Biol Drug Des 83(4):482

34. Upadhyay HC, Thakur JP, Saikia D, Srivastava SK (2013) Med Chem Res 22:16

35. Mohanty S, Gautam Y, Maurya AK et al (2016) Chem Biol Interact 245:12

36. Prado-Prado FJ, García-Mera X, González-Díaz H (2010) Bioorg Med Chem 18(6):2225

37. Prakash O, Khan F, Sangwan RS, Misra L (2013) Comb Chem High Throughput Screen 16(1):57

38. Niwayama S, Turk BE, Liu JO (1996) J Med Chem 39(16):3044

39. Bawankule DU, Chattopadhyay SK, Pal A et al (2008) Inflammopharmacology 16(6):272

40. Singh R, Trivedi P, Bawankule DU et al (2012) J Ethnopharmacol 141(1):357

41. Sharma S, Chattopadhyay SK, Yadav DK et al (2012) Eur J Pharm Sci 47(5):952

Publisher's Note Springer Nature remains neutral with regard to jurisdictional claims in published maps and institutional affiliations. 